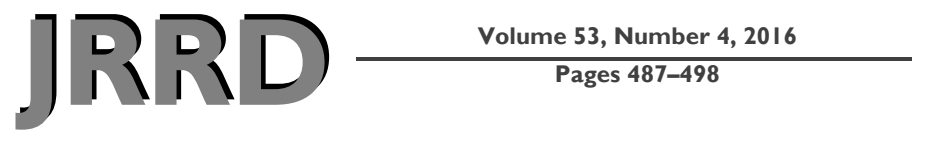

\title{
Capturing nighttime symptoms in Parkinson disease: Technical development and experimental verification of inertial sensors for nocturnal hypokinesia
}

\author{
Roongroj Bhidayasiri, MD, FRCP, FRCPI; ${ }^{1-2^{*}}$ Jirada Sringean, MD; $^{1}$ Poonpak Taechalertpaisarn, EE; ${ }^{1}$ \\ Chusak Thanawattano, $\mathbf{P h D}^{3}$ \\ ${ }^{1}$ Chulalongkorn Center of Excellence for Parkinson Disease \& Related Disorders, Department of Medicine, Faculty of \\ Medicine, Chulalongkorn University and King Chulalongkorn Memorial Hospital, Thai Red Cross Society, Bangkok, \\ Thailand; ${ }^{2}$ Department of Rehabilitation Medicine, Juntendo University, Tokyo, Japan; ${ }^{3}$ Biomedical Signal Processing \\ Laboratory, National Electronics and Computer Technology Center, Pathumthani, Thailand
}

\begin{abstract}
Although nocturnal hypokinesia represents one of the most common nocturnal disabilities in Parkinson disease (PD), it is often a neglected problem in daily clinical practice. We have developed a portable ambulatory motion recorder (the NIGHT-Recorder), which consists of 16-bit triaxial integrated microelectromechanical system inertial sensors that are specifically designed to measure movements, register the position of the body with respect to gravity, and provide information on rotations on the longitudinal axis while lying in bed. The signal processing uses the forward derivative method to identify rolling over and getting out of bed as primary indicators. The prototype was tested on six PD pairs to measure their movements for one night. Using predetermined definitions, 134 movements were captured consisting of rolling over 115 times and getting out of bed 19 times. Patients with PD rolled over significantly fewer times than their spouses $(p=0.03)$, and the position change was significantly smaller in patients with $\operatorname{PD}(p=$ 0.03). Patients with PD rolled over at a significantly slower speed $(p=0.03)$ and acceleration $(p=0.03)$ than their spouses. In contrast, patients with PD got out of bed significantly more often than their spouses $(p=0.02)$. It is technically feasible to develop an easy-to-use, portable, and accurate device that can assist physicians in the assessment of nocturnal movements of patients with PD.
\end{abstract}

Key words: accelerometers, ambulatory monitoring, getting out of bed, inertial sensors, nocturia, nocturnal akinesia, nocturnal hypokinesia, Parkinson disease, quality of life, rolling over, sleep.

\section{INTRODUCTION}

Parkinson disease (PD) is a progressive neurodegenerative disorder with the cardinal features of bradykinesia, rest tremor, rigidity, and postural instability [1]. Nonmotor symptoms (NMSs) in PD increasingly are being recognized in both early and late phases of the disease, and sometimes they are experienced even before the onset of the first motor symptoms, which currently are needed to confirm the diagnosis [2]. The evidence is also clear that the range of NMSs, including autonomic dysfunction, psychiatric complications, pain, fatigue, and sleep problems contribute significantly to poor health-related quality of life in patients with PD [3]. While treatment strategies are widely established for daytime symptoms of

\footnotetext{
Abbreviations: NMS $=$ nonmotor symptom, $\mathrm{PD}=$ Parkinson disease, PDSS $=$ Parkinson Disease Sleep Scale, SD = secure digital.

*Address all correspondence to Roongroj Bhidayasiri, MD, FRCP, FRCPI; Chulalongkorn Center of Excellence for Parkinson Disease \& Related Disorders, Chulalongkorn University and King Chulalongkorn Memorial Hospital, 1873 Rama 4 Rd, Bangkok 10330, Thailand; 662-256-4627; fax: 662-256-4630. Email: rbh@chulapd.org http://dx.doi.org/10.1682/JRRD.2015.04.0062
} 
$\mathrm{PD}$, nighttime problems often are neglected in clinical practice [4]. The inadequate recognition of nighttime problems in PD may be due to a lack of awareness by both patients and treating physicians that these symptoms are PD-related and the inability of patients to articulate their nighttime problems during consultations. Depending on the instruments used to assess nocturnal symptoms, disturbances during the night are reported to be very common among patients with PD. A recent study found that 96.6 percent of patients had at least one nocturnal symptom based on the criteria developed for the modified version of the Parkinson Disease Sleep Scale (PDSS) [5]. Nocturnal symptoms of PD should not be viewed as solely a nighttime problem. It is more accurate to consider them as part of a continuum of manifestations that primarily occur in the night, but with a significant effect on patients' symptoms and functioning during the day as well. Recent studies also provide strong evidence of a negative effect of nocturnal symptoms on patients' quality of life and increased caregiver burden [6-7].

Nocturnal symptoms in PD can be categorized into four groups: (1) PD-related motoric symptoms and nocturia, (2) treatment-related nocturnal disturbances, (3) psychiatric symptoms, and (4) other sleep disorders [8]. Among motoric symptoms, inability to turn over in bed was rated as the most troublesome symptom and affected 45 to 80 percent of patients with PD with insomnia [9]. The ability to roll over is an important sleep movement because it can enable the person to change positions, which can reduce the severity of breathing disorders or pressure sores that may occur in patients with PD while sleeping [10]. Symptoms may last throughout the night and extend to the early morning upon waking, including difficulty getting out of bed unaided, severe tremor, foot dystonia, and painful leg cramps [11-12]. Sleep problems (middle and late night insomnia and daytime sleepiness) were also considered by many patients with advanced PD as their most troublesome symptoms [13]. These problems are not usually evident during the daytime but frequently occur with excessive daytime somnolence and fatigue, although recent evidence suggests that these symptoms are not highly correlated [14-15]. It is also difficult for physicians to recognize specific nocturnal symptoms in individual patients and focus the treatment regimen accordingly $[14,16]$. It is considered good practice for physicians to take the initiative and raise the issue of nocturnal problems with their patients if they are suspected during routine consultations [17]. For these reasons, there is a need to develop instruments that are clin- ically applicable and can assist the treating physicians in developing treatment regimens and rehabilitation programs based on an accurate diagnosis of nocturnal symptoms.

Currently, there are various methods that can help determine the presence of nocturnal symptoms in patients with PD. Most are in the form of surveys and questionnaires. Earlier practice used nonformalized surveys to identify nighttime problems in PD [18-19]. Specific scales, such as the PDSS, the Pittsburgh Sleep Quality Index, and the Scales for Outcomes in PD-Sleep have been developed specifically to evaluate sleep and nocturnal disabilities in PD [20-22]. Recently, our group has modified the PDSS to capture more nocturnal symptom domains and provide evidence for the relationship between nocturnal manifestations of PD and daytime wearing-off [5]. With the advances in sensor technology, there is increased interest in the ambulatory assessment of symptoms in PD [23-25], but very few studies have been dedicated to the objective monitoring of nocturnal symptoms [26-27]. Actigraphy (Actiwatch AW4, Cambridge Neurotechnology Ltd; Cambridgeshire, United Kingdom, and Actiwatch L, Philips Respironics; Andover, Massachusetts) is a small, wrist watch-sized activity monitor that can register and quantify physical activity. It has been tested to estimate information about sleep variables (e.g., total sleep time, sleep efficiency, wake after sleep onset, number of wake bouts, daytime napping), with results compared with the gold-standard overnight polysomnography in patients with PD [28-30]. However, a significant degree of variability in individual patients with PD still occurs with actigraphy, limiting its use in daily clinical practice. Since the inability to turn over in bed is the major manifestation of nocturnal hypokinesia and preliminary evidence suggests that patients with PD change their position in bed less frequently than do nondisabled elderly people [11,31], we sought to develop an inertial sensor that can provide quantitative monitoring of axial rotation of patients with PD and their spouses while in bed.

\section{METHODS}

\section{Design and Fabrication}

To detect rolling over in bed and related sleep disruptions, a device is needed to accurately measure the body position and movements throughout the sleep period. Chulalongkorn Centre of Excellence on Parkinson 
Disease \& Related Disorders has collaborated with Thailand's National Electronics and Computer Technology Center to develop a portable ambulatory motion recorder (the NIGHT-Recorder) specifically for this purpose. The NIGHT-Recorder is composed of five modules: a microcontroller, a power management module, a sensor module, a real-time clock module, and a data storage module (Figure 1). The NIGHT-Recorder is powered by a single AA battery $(1,000 \mathrm{~mA} \cdot \mathrm{h})$. With power consumption of $30 \mathrm{~mW}$, the device can record up to $50 \mathrm{~h}$ or about 6 nights for a regular $8 \mathrm{~h}$ sleep period. The sensor module consists of 16-bit digital-output triaxial integrated microelectromechanical system accelerometers and gyroscope $(3 \times$ $5 \times 1 \mathrm{~mm}, 0.18-0.7 \mathrm{~mA}$ ) capable of measuring linear and angular acceleration in three translational planes $(x, y, z)$. Figure 2 shows the axis arrangement of the sensor with the transverse plane of the chest representing the $y$-axis. This device has been specifically designed to measure movements and to determine the position of a human body with respect to gravity, providing information on rotations in the longitudinal axis while lying in bed. The accelerometer utilizes a differentiable capacitor with central plates attached to the moving mass and fixed external plates. The detected acceleration unbalances the capacitor, resulting in the output wave of the accelerometer.

The NIGHT-Recorder was mounted on a lightweight plastic module, $45 \times 65 \times 23 \mathrm{~mm}$, weight $28.9 \mathrm{~g}$, with offset and temperature drift compensation (Figure 1). The device was calibrated by measuring the signal under controlled inclination, i.e., by rotating the device to provide a

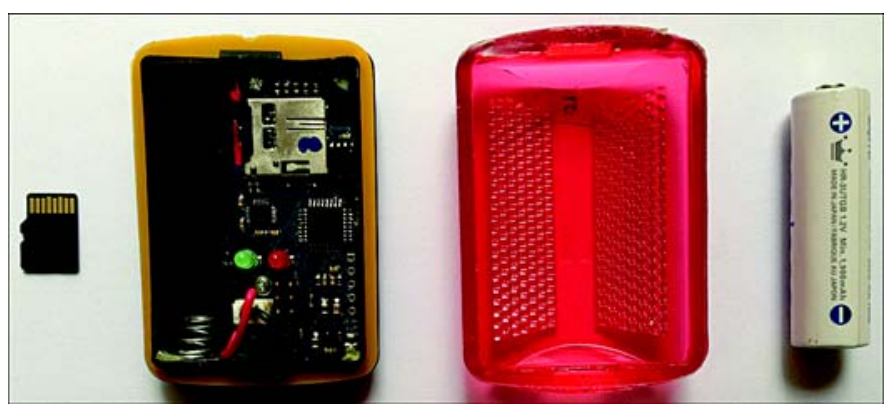

Figure 1.

Configuration of NIGHT-Recorder consisting of five modules: microcontroller, power management module, sensor module, real-time clock module, and data storage module. It is powered by single AA battery (1,000 mA.h), and data are stored on $1 \mathrm{~GB}$ secure digital memory card.

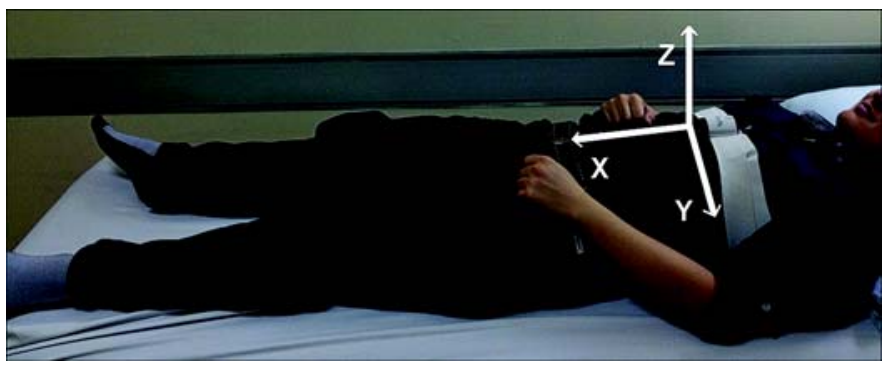

Figure 2.

Axis orientation of NIGHT-Recorder when worn at sternum about $5 \mathrm{~cm}$ below jugulum. Sensitive axis ( $y$-axis) for body rollover was in transverse horizontal plane to frontal aspect of sternum, dorsum of lower arm segment, frontal aspect of thigh, and lower-leg segment.

signal output corresponding to +1 and $-1 g$ (gravitational acceleration). However, it can provide a programmable full-scale range of $\pm 2 \mathrm{~g}, \pm 4 \mathrm{~g}, \pm 8 \mathrm{~g}$, and $\pm 16 \mathrm{~g}$. With the full-scale range set to $\pm 8 \mathrm{~g}$, the smallest change the sensor can detect is $2.44 \times 10^{-4} \mathrm{~g}$, or $2.39 \mathrm{~mm} / \mathrm{s}^{2}$. The direct current output is 0 when the sensitive axis is parallel to the gravitational axis. The recordings were obtained with a $10 \mathrm{~Hz}$ sampling rate, and data were stored on a $1 \mathrm{~GB}$ secure digital (SD) memory card in comma-separated value format. Each hour of recording constitutes $950 \mathrm{kB}$ of data for storage. A higher sampling rate was considered unnecessary for recording nocturnal movements, in which the movements tend to be slow.

The NIGHT-Recorder was fastened with Velcro bands and worn above the nightclothes at the sternum about $5 \mathrm{~cm}$ below the jugulum, chosen because it is a rigid body structure close to the center of mass and to reduce artifacts caused by arm movements. The sensitive axis (y-axis) for body rollover was in a transverse horizontal plane to the frontal aspect of the sternum, the dorsum of the lower arm segment, the frontal aspect of the thigh, and the lower leg segment (Figure 2). The cost of production of the whole system including the analysis software was approximately $\$ 800$.

\section{Detection of Rolling Over in Bed}

Rolling over in bed is defined as a series of unconscious motions during sleep involving rotational body movements [32]. In our study, we adopted the operational definition of rolling over as a series of at least a $15^{\circ}$ rotational movement of the trunk from one static position to another that is sustained for at least $5 \mathrm{~min}$ in a $y$-axis 
plane. This criterion was applied in some previous studies, although the period of sustained duration varied [26,31]. The movement of limbs was not considered as rolling over. In addition, we identified getting out of bed or sitting up activities from the recording by a rapid rise of acceleration in the $x$-axis of more than $45^{\circ}$ from either static or rotational movements [33].

\section{Signal Processing}

After one night recording, the data were transferred from the SD memory card to the workstation computer running a high-level language software for signal processing and analysis. After checking that signal output corresponded to +1 and $-1 \mathrm{~g}$, the data in the gravity unit were multiplied by a factor of 90 to convert to the angular data in degrees. Then, the angular data were filtered to dispose of high frequency (noisy) components by applying a moving-average filter of 21 samples with the following equation:

$$
y(n)=\frac{1}{21}+x(n)+\frac{1}{21} x(n-1)+\frac{1}{21} x(n-2)+\ldots+\frac{1}{21} x(n-20) .
$$

To reduce computational time while maintaining consistent results, the average filter was down-sampled by a factor of 60 , resulting in the sampling rate of $10 / \mathrm{min}$. We found that this sampling rate is sufficient for the relatively slow movement at night.

To detect body rollover according to the aforementioned criteria, we performed the forward derivative method on the angular data to obtain its derivatives. Samples of the derivative signals that had values of larger than $+15^{\circ}$ or smaller than $-15^{\circ}$ were identified as potential samples. The positive and negative values indicated the direction of the rollover, i.e., positive values for right turns and negative values for left turns accordingly. Then, the software only marked the samples that fit the operational definition of sustaining in a new static position for longer than $5 \mathrm{~min}$. Similar procedures but with different criteria were also applied to the same set of data to obtain the getting out of bed activities. Figures $\mathbf{3}$ and $\mathbf{4}$ show samples of the data set demonstrating rolling over and getting out of bed activities in one patient with PD and his spouse.

\section{Experimental Verification}

After the study was approved by the Human Ethical Committee of the Faculty of Medicine of Chulalongkorn University, 12 subjects (6 patients with PD and their spouses) were invited to participate in the study as part of the experimental verification to record their nocturnal movements for one night. Six patients were evaluated by two independent movement disorder neurologists, whose assessment was based on clinical findings and examinations. They assigned the diagnosis of PD using the United Kingdom Parkinson Disease Society Brain Bank diagnostic criteria [34]. In addition, all spouses were carefully examined by the same set of neurologists and deemed not to have any signs of parkinsonism. Subjects who were bed bound, took sedatives or hypnotics, or were diagnosed with any axial musculoskeletal disorders were excluded from the study. All participants provided informed consent.

\section{Experimental Procedure}

The experiment was conducted in the patients' own bedrooms without any changes or modification of their sleeping environment. All subjects were set up with the NIGHT-Recorder placed at the sternum as described previously. The whole setup took less than 15 min. Subjects were instructed to complete a sleep diary for sleep times and the episodes of getting out of bed if awakened. Sleep times were defined as the period that the subjects were in bed excluding the first and last $5 \mathrm{~min}$. If any discrepancies occurred between sleep times as provided by subjects' records and sleep times registered by the accelerometer, the registration by the accelerometer was synchronized with the data reported by the subjects. The characteristics of rolling over include degrees, duration, velocity, and acceleration. Figure $\mathbf{5}$ describes different outcome parameters in categories, descriptions, and units.

\section{Statistical Analysis}

Anonymous data, conforming to data protection legislation in Thailand, were transferred to the Chulalongkorn Centre of Excellence on Parkinson Disease \& Related Disorders for detailed statistical analysis. Baseline characteristics of both patients with PD and their spouses were summarized using either means and standard deviation or frequencies and percentages as appropriate. Wilcoxon matched-pairs signed-ranks test was used for comparison of outcome parameters between patients with PD and their spouses. A $p$-value $<0.05$ was considered statistically significant. Statistical analysis was performed using SPSS version 17.0 (IBM Corporation; Armonk, New York). 

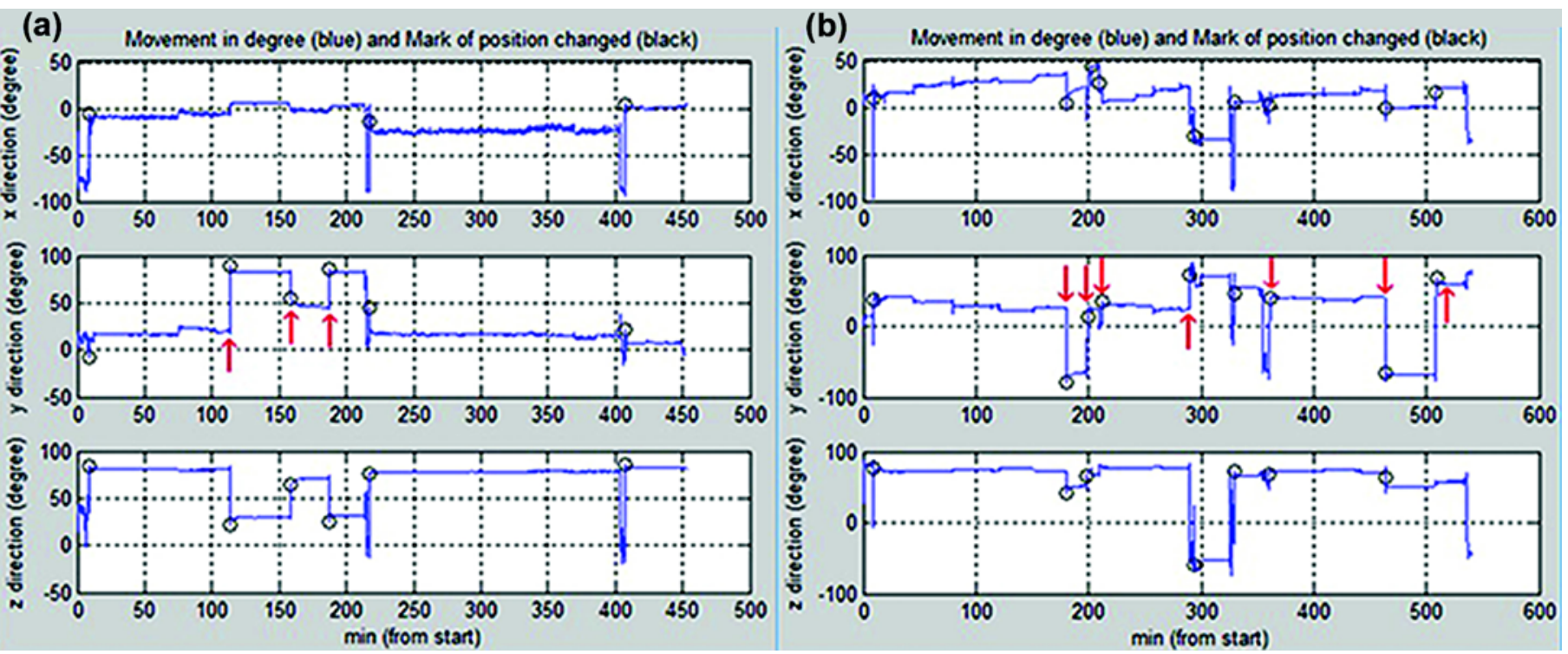

Figure 3.

Samples of data set demonstrating rolling over (red arrow) activities in (a) patient with Parkinson disease and (b) his spouse. Episode of rolling over is automatically captured by forward derivative method when there is at least $15^{\circ}$ rotational movement of trunk from one static position to another that sustains for at least 5 min in $y$-axis plane.

(a)
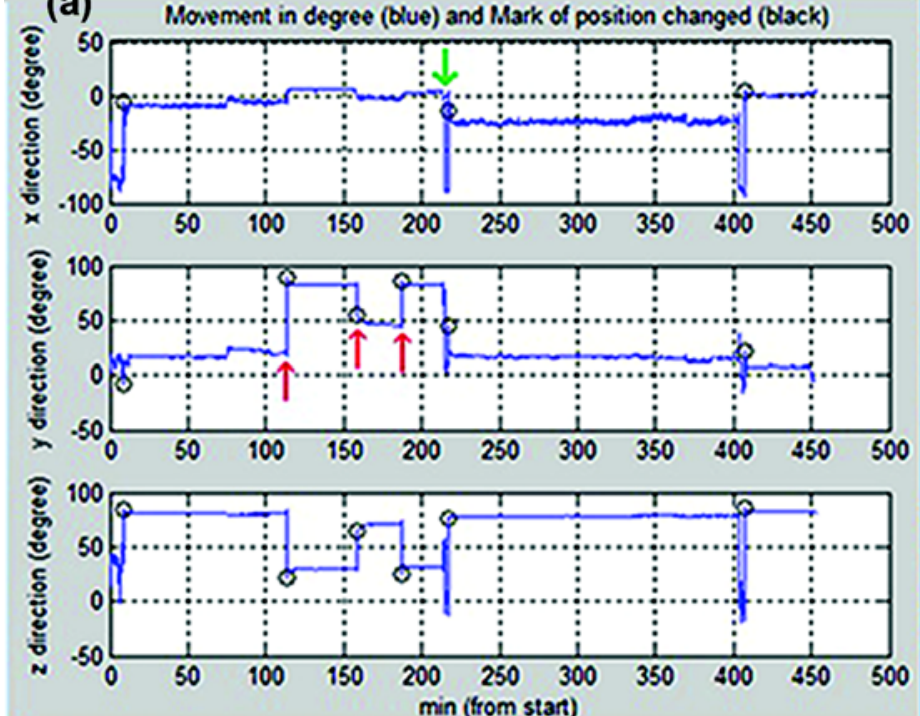

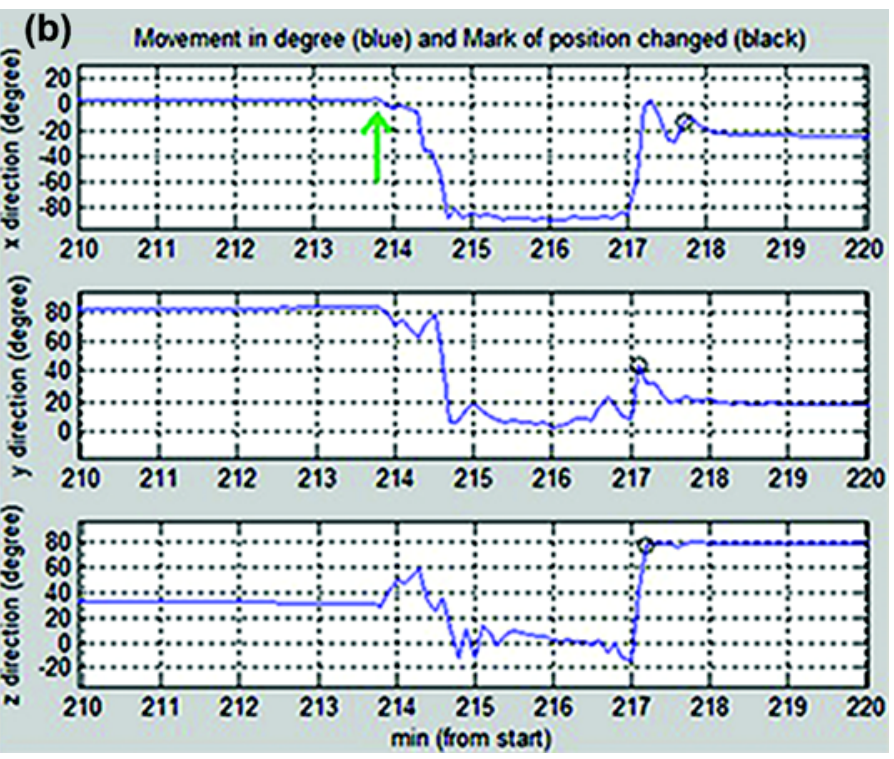

Figure 4.

Samples of data set demonstrating episode of getting out of bed (green arrow) in (a) patient with Parkinson disease. Getting out of bed activity is automatically captured when there is rise of acceleration in $x$-axis of more than $45^{\circ}$ from either static or rotational movement. (b) Signals amplified to larger scale. Red arrows identified rolling over episodes. 
Duration of Sleep (min): Total period while in bed excluding first and last 5 min.

Axial Movements (rolling over): Series of at least $15^{\circ}$ rotational movement of trunk from one static position to another static position that sustains for at least 5 min in $y$-axis plane.

Getting Out of Bed: Rapid rise of acceleration in $x$-axis of more than $45^{\circ}$ from either static or rotational movement.

Frequency (movements/h): Number of rolling over per hour of in-bed period.

Size $\left({ }^{\circ}\right)$ : Angle of change in position resulting from axial movement.

Duration of Rolling Over (s): Time spent on one episode of rolling over.

Velocity (radians/s): Mean size per second of axial movement.

Acceleration (radians $/ \mathrm{s}^{2}$ ): Rate of velocity change during axial movement.

Figure 5.

Definitions of nocturnal movement parameters used in study.

\section{RESULTS}

Table 1 shows the demographic data and disease characteristics of all subjects. There were no significant differences between age, weight, body mass index, and sleep duration between patients and their spouses. All subjects were right handed. All participants were able to complete a one-night assessment with the NIGHTRecorder without any adverse events. All subjects wore the devices comfortably and did not feel the heat transmitted from the device on their skin. The sleep duration was not significantly different between patients with PD and their spouses. Mean disease duration of patients with PD was $10.8 \pm 6.2$ yr. In total, 134 movements were captured: 115 rolling over and 19 getting out of bed activities. Patients with PD had fewer episodes of rolling over than their spouses $(p=0.03)$, and the degree of rolling over was smaller in patients with $\operatorname{PD}(p=0.03)$. While the duration of turns between the two groups was not statistically significant, patients with PD rolled at a slower speed $(p=0.03)$ and acceleration $(p=0.03)$ than their spouses. In contrast, patients with PD had more episodes of rising from bed activities than their spouses $(p=0.02)$. Pearson correlation and scattered plots were also per- formed to determine the validity of each parameter (see Appendix, available online only). These episodes were verified with each of the subject's corresponding sleep diary to identify that the purposes of all getting up episodes were nocturia. While four out of six patients with PD (67\%) had fewer episodes of rolling over in the latter half of the night, nocturia was observed throughout the night in all six patients with PD. Table 2 gives an overview of these data.

\section{DISCUSSION}

The aim of our study was to develop a device (the NIGHT-Recorder) that can capture axial rotational movements in PD. We hypothesized that patients with PD might show different axial nocturnal movement patterns than their spouses, but we only focused on the rolling over and getting out of bed activities in this analysis. Our study provides an example of an accelerometer in a proper orientation that can be developed technically and with the required accuracy of measuring the kinematics of axial rotations at night. Moreover, the device is easy to set up and portable. The development of this device is

Table 1.

Demographic data of patients with Parkinson disease (PD) $(n=6)$ and their spouses $(n=6)$. Data given as mean \pm standard deviation.

\begin{tabular}{lccc}
\hline \multicolumn{1}{c}{ Variable } & Patients with PD & Spouses & p-Value \\
\hline Male $(n)$ & 6 & $66.67 \pm 7.76$ & - \\
Age $(\mathrm{yr})$ & $65.50 \pm 7.45$ & $66.50 \pm 14.95$ & 0.88 \\
Weight $(\mathrm{kg})$ & $69.67 \pm 14.46$ & $26.83 \pm 5.71$ & 0.35 \\
Body Mass Index & $24.30 \pm 4.15$ & - & 0.25 \\
Disease Duration (yr) & $10.8 \pm 6.2$ & - & - \\
Hoehn \& Yahr Stage & $2.25 \pm 1.13$ & - \\
Unified Parkinson Disease Rating Scale & $21.5 \pm 10.7$ & - & - \\
\hline \hline
\end{tabular}


Table 2.

Nocturnal movement parameters in patients with Parkinson disease (PD) $(n=6)$ and their spouses $(n=6)$. Data given as mean \pm standard deviation unless otherwise noted.

\begin{tabular}{lccc}
\hline \multicolumn{1}{c}{ Parameter } & Patients with PD & Spouses & p-Value \\
Sleep Duration (min) & $539.50 \pm 83.98$ & $454.50 \pm 74.24$ & 0.17 \\
Total No. of Movements $(n)$ & 35 & 99 & $0.02^{*}$ \\
Getting Out of Bed $(n)$ & $2.17 \pm 0.75$ & $1.00 \pm 0.89$ & $0.03^{*}$ \\
Rolling Over $(n)$ & $3.67 \pm 2.50$ & $15.50 \pm 10.54$ & $0.03^{*}$ \\
Frequency (movements/h) & $0.39 \pm 0.24$ & $2.04 \pm 1.25$ & $0.03^{*}$ \\
Size $\left({ }^{\circ}\right)$ & $40.37 \pm 11.78$ & $81.42 \pm 8.40$ & 0.46 \\
Duration of Rolling Over (s) & $12.02 \pm 3.83$ & $14.76 \pm 5.12$ & $0.03^{*}$ \\
Speed (radians/s) & $0.08 \pm 0.02$ & $0.14 \pm 0.03$ & $0.03^{*}$ \\
Acceleration (radians/s & & \\
${ }^{*}$ ) & $0.06 \pm 0.03$ & $0.18 \pm 0.04$ & \\
\hline
\end{tabular}

*Statistical significance.

No. = number.

relatively inexpensive, with a potential for clinical applications for nocturnal assessment in patients with PD.

Although the data cannot as yet be generalized, the results of axial nocturnal movements in our pilot study have identified several characteristics of the problems of rolling over among patients with $\mathrm{PD}$, including less frequent turns, smaller turns, and slower turns when compared with matched spouses. These findings reinforce previous observations of nocturnal hypokinesia-mostly conducted in the form of questionnaires and interviewsshowing that impaired bed mobility exists and is likely to contribute to a wide range of nocturnal motor symptoms and NMSs in patients with PD, such as stiffness, rigidity, pain, breathing disorders, nocturia, or even insomnia [5,9,18-19,35-37]. Moreover, a number of recent studies support the negative effects of nocturnal hypokinesia on the overall sleep quality, daytime symptoms, and quality of life of both patients as well as caregivers [5,7,35-37].

There are several mechanisms underlying the axial disability in patients with PD. Primarily, axial disability is the clinical manifestation of the disease itself once the progression has reached the Hoehn and Yahr scale of at least stage 3 or more [38]. It appears that disorders of axial movements in patients with PD are dependent on the duration of the disease progression and associated increases in severity because of neurodegeneration [39]. However, the aging process on nondopaminergic subcortical structures has been found to contribute to the axial impairment in PD [40]. Changes in postural alignment, such as camptocormia, Pisa syndrome, and scoliosis can also pose additional mechanical limitation when patients with PD attempt to roll over [41]. Moreover, the loss of automatic associated movements at night causes the dis- ruption of limb and axial movement sequences and is probably another contributing factor to the problems of rolling over in PD patients [39]. Certain medications, such as neuroleptics, may have an effect on the ability of patients with PD to turn at night.

Detection of the rolling over problems in PD has important clinical implications, particularly in the area of rehabilitation. Because failure to turn in bed is associated with gait disturbances, postural instability, axial rigidity, whole body bradykinesia, and difficulty rising from a chair, identification of impaired bed motility is likely to lead to early intervention of axial disability in PD, which is now considered as the index of disease progression $[39,42]$. A study that evaluated the movement patterns used by patients with PD for rising from bed indicated that patients with PD were significantly less likely to vary the pattern of movement that they used for their trunk and head than older adults without PD, suggesting that there may be more constraints on degrees of freedom in the axial region for people with PD [43]. The rehabilitation program could impose a series of exercise training for turning in bed and teaching appropriate strategies for getting out of bed $[9,43]$. Identifying those at risk and starting early rehabilitation could potentially reduce the risk of falling since the majority of falls in PD happen at home, commonly in bedrooms when patients attempt to get out of bed to go to the toilet [44]. Recent evidence also suggests that physicians should be more proactive in referring patients with PD (particularly Veterans with PD) to physical therapy and encouraging their participation in exercise [45]. Because the ability to turn in bed can be dopamine responsive, physicians have the option of adjusting dopaminergic medications to improve nocturnal 
akinesia once identified [46-47]. Since our preliminary results suggested that nocturnal hypokinesia was probably more evident during the latter half of the night, therapeutic trial of levodopa at bedtime is unlikely to be of benefit because of its short half-life. However, these early findings should be properly evaluated in large randomized controlled trials because the findings could have a significant therapeutic implication on what treatment will be the most appropriate for patients with PD with nocturnal hypokinesia (e.g., long-acting dopamine agonists). Adequate treatment of nocturnal akinesia can probably prevent other complications, such as pressure sores, breathing disorders, and aspiration, which are common in patients with advanced PD. From a diagnostic perspective, subclinical axial movement alternations at night may be an important marker for early diagnosis. However, this proposal was not confirmed in one recent study involving 33 subjects with a high risk of developing PD [26].

\section{CONCLUSIONS}

With the advances in circuit technology, sensors have become smaller in size and better in performance, resulting in an emerging interest in this technology in the ambulatory assessment of nighttime symptoms in patients with PD. Indeed, the majority of smartphones and portable media devices nowadays are also equipped with sensor components, such as accelerometers. Our study has provided a proof of principle that it is technically feasible to develop an easy-to-use, portable, accurate, and cost-effective device that can assist physicians in the nocturnal assessment of patients with PD. Considering it is often difficult for patients to provide adequate clinical information on their nighttime problems to their treating physicians, we hope that this system can provide objective evidence of the impairment of rollover and result in appropriate intervention to improve the nighttime symptoms and quality of life of patients with PD. The application of this tool may extend to patients with other disorders that affect nighttime mobility, such as atypical parkinsonian disorders [48]. Since our research focuses on the identification of rolling over, additional studies are needed to develop the protocol to assess the full spectrum of nocturnal akinesia in patients with PD. By utilizing multisite accelerometers, additional information can be gained if we can objectively capture various movement disorders that may occur nocturnally in patients with PD. Furthermore, the device can also be used to study various bed turning strategies in patients with PD, which are an important source of information for therapists in providing comprehensive rehabilitation in order to prevent nocturnal complications associated with PD.

\section{ACKNOWLEDGMENTS}

\section{Author Contributions:}

Study concept and design: R. Bhidayasiri.

Study organization and execution: R. Bhidayasiri, J. Sringean, P. Taechalertpaisarn, C. Thanawattano.

Design of statistical analysis: R. Bhidayasiri, J. Sringean.

Review and critique of statistical analysis: P. Taechalertpaisarn. Drafting of manuscript: R. Bhidayasiri, J. Sringean.

Critical revision of manuscript for important intellectual content: R. Bhidayasiri, C. Thanawattano.

Financial Disclosures: The authors have declared that no competing interests exist.

Funding/Support: This material was based on work supported by the Ratchadapiseksompoj Endowment Fund of Chulalongkorn University (grants RES560530136 and RES560530137-HR), the National

Research Council of Thailand (grant GRB-APS-13-58-30-10), Chulalongkorn University (research unit grant RA57/119), and a Cerebos award grant from Cerebos Thailand.

Institutional Review: This study was approved by the Human Ethical Committee of the Faculty of Medicine of Chulalongkorn University. All participants signed informed consent.

Participant Follow-up: The authors do not plan to inform participants of the publication of this study. However, participants have been encouraged to check the study Web site for updated publications.

\section{REFERENCES}

1. Lang AE, Lozano AM. Parkinson's disease. First of two parts. N Engl J Med. 1998;339(15):1044-53.

[PMID:9761807]

http://dx.doi.org/10.1056/NEJM199810083391506

2. Truong DD, Bhidayasiri R, Wolters E. Management of non-motor symptoms in advanced Parkinson disease. J Neurol Sci. 2008;266(1-2):216-28. [PMID:17804018] http://dx.doi.org/10.1016/j.jns.2007.08.015

3. Gallagher DA, Lees AJ, Schrag A. What are the most important nonmotor symptoms in patients with Parkinson's disease and are we missing them? Mov Disord. 2010; 25(15):2493-2500. [PMID:20922807]

http://dx.doi.org/10.1002/mds.23394

4. Chaudhuri KR. The basis for day and night-time control of symptoms of Parkinson's disease. Eur J Neurol. 2002; 
9(Suppl 3):40-43. [PMID:12464120]

http://dx.doi.org/10.1046/j.1468-1331.9.s3.5.x

5. Bhidayasiri R, Mekawichai P, Jitkritsadakul O, Panyakaew P, Kaewwilai L, Boonrod N, Petchrutchatachart S, Jagota P, Boonpeng K, Singmaneesakulchai S, Setthawatcharawanich S. Nocturnal journey of body and mind in Parkinson's disease: The manifestations, risk factors and their relationship to daytime symptoms. Evidence from the NIGHT-PD study. J Neural Transm. 2014;121(Suppl 1):S59-68.

[PMID:24682359]

http://dx.doi.org/10.1007/s00702-014-1199-X

6. Martinez-Martin P, Rodriguez-Blazquez C, Kurtis MM, Chaudhuri KR; NMSS Validation Group. The impact of non-motor symptoms on health-related quality of life of patients with Parkinson's disease. Mov Disord. 2011; 26(3):399-406. [PMID:21264941]

http://dx.doi.org/10.1002/mds.23462

7. Viwattanakulvanid P, Kaewwilai L, Jitkritsadakul O, Brenden NR, Setthawatcharawanich S, Boonrod N, Mekawichai P, Bhidayasiri R. The impact of the nocturnal disabilities of Parkinson's disease on caregivers' burden: Implications for interventions. J Neural Transm. 2014;121(Suppl 1):S15-24. [PMID:24682360] http://dx.doi.org/10.1007/s00702-014-1200-8

8. Barone P, Amboni M, Vitale C, Bonavita V. Treatment of nocturnal disturbances and excessive daytime sleepiness in Parkinson's disease. Neurology. 2004;63(8 Suppl 3):S35-38. [PMID:15505142] http://dx.doi.org/10.1212/WNL.63.8 suppl 3.S35

9. Stack EL, Ashburn AM. Impaired bed mobility and disordered sleep in Parkinson's disease. Mov Disord. 2006; 21(9):1340-42. [PMID:16773640] http://dx.doi.org/10.1002/mds.20944

10. Szollosi I, Roebuck T, Thompson B, Naughton MT. Lateral sleeping position reduces severity of central sleep apnea/ Cheyne-Stokes respiration. Sleep. 2006;29(8):1045-51. [PMID:16944673]

11. Grandas F, Iranzo A. Nocturnal problems occurring in Parkinson's disease. Neurology. 2004;63(8 Suppl 3):S8-11. [PMID:15505143] http://dx.doi.org/10.1212/WNL.63.8 suppl 3.S8

12. Stocchi F, Barbato L, Nordera G, Berardelli A, Ruggieri S. Sleep disorders in Parkinson's disease. J Neurol. 1998; 245(Suppl 1):S15-18. [PMID:9617717]

http://dx.doi.org/10.1007/PL00007731

13. Politis M, Wu K, Molloy S, G Bain P, Chaudhuri KR, Piccini P. Parkinson's disease symptoms: The patient's perspective. Mov Disord. 2010;25(11):1646-51.

[PMID:20629164] http://dx.doi.org/10.1002/mds.23135

14. Verbaan D, van Rooden SM, Visser M, Marinus J, van Hilten JJ. Nighttime sleep problems and daytime sleepiness in Parkinson’s disease. Mov Disord. 2008;23(1):35-41. [PMID:17960797]

http://dx.doi.org/10.1002/mds.21727

15. Höglund A, Broman JE, Pålhagen S, Fredrikson S, Hagell P. Is excessive daytime sleepiness a separate manifestation in Parkinson's disease? Acta Neurol Scand. 2015;132(2): 97-104. [PMID:25630925]

http://dx.doi.org/10.1111/ane.12378

16. Comella CL. Sleep disorders in Parkinson's disease: An overview. Mov Disord. 2007;22(Suppl 17):S367-73.

[PMID:18175398]

http://dx.doi.org/10.1002/mds.21682

17. Medcalf P. Good practice in the assessment and management of nocturnal Parkinson's disease symptoms. Age Ageing. 2005;34(5):435-38. [PMID:16107451] http://dx.doi.org/10.1093/ageing/afi157

18. Lees AJ, Blackburn NA, Campbell VL. The nighttime problems of Parkinson's disease. Clin Neuropharmacol. 1988;11(6):512-19. [PMID:3233589] http://dx.doi.org/10.1097/00002826-198812000-00004

19. Tandberg E, Larsen JP, Karlsen K. A community-based study of sleep disorders in patients with Parkinson's disease. Mov Disord. 1998;13(6):895-99. [PMID:9827612] http://dx.doi.org/10.1002/mds.870130606

20. Chaudhuri KR, Pal S, DiMarco A, Whately-Smith C, Bridgman K, Mathew R, Pezzela FR, Forbes A, Högl B, Trenkwalder C. The Parkinson's disease sleep scale: A new instrument for assessing sleep and nocturnal disability in Parkinson's disease. J Neurol Neurosurg Psychiatry. 2002; 73(6):629-35. [PMID:12438461] http://dx.doi.org/10.1136/jnnp.73.6.629

21. Marinus J, Visser M, van Hilten JJ, Lammers GJ, Stiggelbout AM. Assessment of sleep and sleepiness in Parkinson disease. Sleep. 2003;26(8):1049-54. [PMID:14746389]

22. Buysse DJ, Reynolds CF 3rd, Monk TH, Berman SR, Kupfer DJ. The Pittsburgh Sleep Quality Index: A new instrument for psychiatric practice and research. Psychiatry Res. 1989;28(2):193-213. [PMID:2748771] http://dx.doi.org/10.1016/0165-1781(89)90047-4

23. Hobert MA, Maetzler W, Aminian K, Chiari L. Technical and clinical view on ambulatory assessment in Parkinson's disease. Acta Neurol Scand. 2014;130(3):139-47.

[PMID:24689772] http://dx.doi.org/10.1111/ane.12248

24. Maetzler W, Domingos J, Srulijes K, Ferreira JJ, Bloem BR. Quantitative wearable sensors for objective assessment of Parkinson’s disease. Mov Disord. 2013;28(12):1628-37. [PMID:24030855]

25. Bhidayasiri R, Petchrutchatachart S, Pongthornseri R, Anan C, Dumnin S, Thanawattano C. Low-cost, 3-dimension, office-based inertial sensors for automated tremor assessment: Technical development and experimental verification. J Parkinsons Dis. 2014;4(2):273-82. [PMID:24613867] 
26. Louter M, Maetzler W, Prinzen J, van Lummel RC, Hobert M, Arends JB, Bloem BR, Streffer J, Berg D, Overeem S, Liepelt-Scarfone I. Accelerometer-based quantitative analysis of axial nocturnal movements differentiates patients with Parkinson's disease, but not high-risk individuals, from controls. J Neurol Neurosurg Psychiatry. 2015; 86(1):32-37. [PMID:24777169] http://dx.doi.org/10.1136/jnnp-2013-306851

27. Yoneyama M, Mitoma H, Okuma Y. Accelerometry-based long-term monitoring of movement disorders: From diurnal gait behavior to nocturnal bed mobility. J Mech Med Biol. 2013;13:1350041. http://dx.doi.org/10.1142/S0219519413500413

28. Maglione JE, Liu L, Neikrug AB, Poon T, Natarajan L, Calderon J, Avanzino JA, Corey-Bloom J, Palmer BW, Loredo JS, Ancoli-Israel S. Actigraphy for the assessment of sleep measures in Parkinson's disease. Sleep. 2013; 36(8):1209-17. [PMID:23904681]

29. Louter M, Arends JB, Bloem BR, Overeem S. Actigraphy as a diagnostic aid for REM sleep behavior disorder in Parkinson's disease. BMC Neurol. 2014;14:76. [PMID:24708629] http://dx.doi.org/10.1186/1471-2377-14-76

30. Bolitho SJ, Naismith SL, Salahuddin P, Terpening Z, Grunstein RR, Lewis SJ. Objective measurement of daytime napping, cognitive dysfunction and subjective sleepiness in Parkinson's disease. PLoS ONE. 2013;8(11): e81233. [PMID:24278399]

http://dx.doi.org/10.1371/journal.pone.0081233

31. Weller C, Bowes SG, Kirk CA, Nicholson PW, Dobbs RJ, Dobbs SM. Measurement of axial rotation: Its relevance to screening for night-time hypokinesia in old age and parkinsonism. Age Ageing. 1991;20(1):3-7. [PMID:2028848] http://dx.doi.org/10.1093/ageing/20.1.3

32. Miwa H, Sasahara S, Matsui T. Roll-over detection and sleep quality measurement using a wearable sensor. Conf Proc IEEE Eng Med Biol Soc. 2007;2007:1507-10. [PMID:18002253]

33. Weller C, Nicholson PW, Dobbs SM, Bowes SG, Purkiss A, Dobbs RJ. Reduced axial rotation in the spouses of sufferers from clinical idiopathic parkinsonism. Age Ageing. 1992;21(3):189-94. [PMID:1615781]

http://dx.doi.org/10.1093/ageing/21.3.189

34. Gibb WR, Lees AJ. The relevance of the Lewy body to the pathogenesis of idiopathic Parkinson's disease. J Neurol Neurosurg Psychiatry. 1988;51(6):745-52.

[PMID:2841426]

http://dx.doi.org/10.1136/jnnp.51.6.745

35. Pal PK, Thennarasu K, Fleming J, Schulzer M, Brown T, Calne SM. Nocturnal sleep disturbances and daytime dysfunction in patients with Parkinson's disease and in their caregivers. Parkinsonism Relat Disord. 2004;10(3):157-68.

\section{[PMID:15036171]}

http://dx.doi.org/10.1016/j.parkreldis.2003.11.002

36. Louter M, Munneke M, Bloem BR, Overeem S. Nocturnal hypokinesia and sleep quality in Parkinson's disease. J Am Geriatr Soc. 2012;60(6):1104-8. [PMID:22642534] http://dx.doi.org/10.1111/j.1532-5415.2012.03966.x

37. Louter M, van Sloun RJ, Pevernagie DA, Arends JB, Cluitmans PJ, Bloem BR, Overeem S. Subjectively impaired bed mobility in Parkinson disease affects sleep efficiency. Sleep Med. 2013;14(7):668-74. [PMID:23643658] http://dx.doi.org/10.1016/j.sleep.2013.03.010

38. Hoehn MM, Yahr MD. Parkinsonism: Onset, progression and mortality. Neurology. 1967;17(5):427-42. [PMID:6067254] http://dx.doi.org/10.1212/WNL.17.5.427

39. Steiger MJ, Thompson PD, Marsden CD. Disordered axial movement in Parkinson's disease. J Neurol Neurosurg Psychiatry. 1996;61(6):645-48. [PMID:8971118] http://dx.doi.org/10.1136/jnnp.61.6.645

40. Levy G, Louis ED, Cote L, Perez M, Mejia-Santana H, Andrews H, Harris J, Waters C, Ford B, Frucht S, Fahn S, Marder K. Contribution of aging to the severity of different motor signs in Parkinson disease. Arch Neurol. 2005;62(3): 467-72. [PMID:15767513] http://dx.doi.org/10.1001/archneur.62.3.467

41. Doherty KM, van de Warrenburg BP, Peralta MC, SilveiraMoriyama L, Azulay JP, Gershanik OS, Bloem BR. Postural deformities in Parkinson's disease. Lancet Neurol. 2011;10(6):538-49. [PMID:21514890] http://dx.doi.org/10.1016/S1474-4422(11)70067-9

42. Evans JR, Mason SL, Williams-Gray CH, Foltynie T, Brayne C, Robbins TW, Barker RA. The natural history of treated Parkinson's disease in an incident, community based cohort. J Neurol Neurosurg Psychiatry. 2011;82(10): 1112-18. [PMID:21593513] http://dx.doi.org/10.1136/jnnp.2011.240366

43. Mount J, Cianci H, Weiman R, Da Costa J, Tabibian H, Prochaska J. How people with Parkinson's disease get out of bed. Phys Occup Ther Geriatr. 2009;27(5):333-59. http://dx.doi.org/10.1080/02703180802560934

44. Ashburn A, Stack E, Ballinger C, Fazakarley L, Fitton C. The circumstances of falls among people with Parkinson's disease and the use of Falls Diaries to facilitate reporting. Disabil Rehabil. 2008;30(16):1205-12. [PMID:18608387] http://dx.doi.org/10.1080/09638280701828930

45. Trail M, Petersen NJ, Nelson N, Lai EC. An exploratory study of activity in veterans with Parkinson's disease. J Neurol. 2012;259(8):1686-93. [PMID:22289964] http://dx.doi.org/10.1007/s00415-011-6400-7

46. Trenkwalder C, Kies B, Rudzinska M, Fine J, Nikl J, Honczarenko K, Dioszeghy P, Hill D, Anderson T, Myllyla V, Kassubek J, Steiger M, Zucconi M, Tolosa E, Poewe W, 
Surmann E, Whitesides J, Boroojerdi B, Chaudhuri KR; Recover Study Group. Rotigotine effects on early morning motor function and sleep in Parkinson's disease: A doubleblind, randomized, placebo-controlled study (RECOVER). Mov Disord. 2011;26(1):90-99. [PMID:21322021] http://dx.doi.org/10.1002/mds.23441

47. Ray Chaudhuri K, Martinez-Martin P, Rolfe KA, Cooper J, Rockett CB, Giorgi L, Ondo WG. Improvements in nocturnal symptoms with ropinirole prolonged release in patients with advanced Parkinson's disease. Eur J Neurol. 2012; 19(1):105-13. [PMID:21699627] http://dx.doi.org/10.1111/j.1468-1331.2011.03442.x

48. Bhidayasiri R, Jitkritsadakul O, Colosimo C. Nocturnal manifestations of atypical parkinsonian disorders. J Parkinsons Dis. 2014;4(2):223-36. [PMID:24705593]

Submitted for publication April 10, 2015. Accepted in revised form July 17, 2015.
This article and any supplementary material should be cited as follows:

Bhidayasiri R, Sringean J, Taechalertpaisarn P, Thanawattano C. Capturing nighttime symptoms in Parkinson disease: Technical development and experimental verification of inertial sensors for nocturnal hypokinesia. J Rehabil Res Dev. 2016;53(4):487-98. http://dx.doi.org/10.1682/JRRD.2015.04.0062

ORCID: Roongroj Bhidayasiri, MD, FRCP, FRCPI: 0000-0002-6901-2064

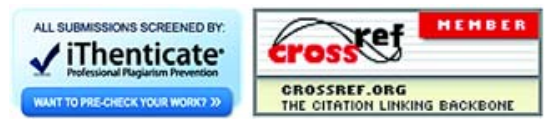


